\title{
Use of the Fix and Flap Approach to Complex Open Elbow Injury: The Role of the Free Anterolateral Thigh Flap
}

\author{
Christopher Hoe-Kong Chui ${ }^{1}$, Chin-Ho Wong ${ }^{1}$, Winston Y Chew ${ }^{2}$, Mun-Hon Low ${ }^{3}$, \\ Bien-Keem Tan ${ }^{1}$ \\ ${ }^{1}$ Department of Plastic, Reconstructive and Aesthetic Surgery, Singapore General Hospital; ${ }^{2}$ Department of Orthopaedic Surgery (Hand and \\ Microsurgery), Tan Tock Seng Hospital; ${ }^{3}$ Department of Orthopaedic Surgery, Singapore General Hospital, Singapore
}

Background Complex elbow injuries with associated nerve, muscle, or joint injury commonly develop post-inury stiffness. In order to preserve function, joint congruency, elbow stability and durable wound coverage must be achieved in a timely manner.

Methods A retrospective review of patients who underwent orthopaedic fixation followed by free anterolateral thigh (ALT) flap soft tissue coverage was performed. Five patients were identified and included in this study.

Results We present a series of 5 cases managed with this principle. Soft tissue defects ranged in size from $4 \times 9 \mathrm{~cm}\left(36 \mathrm{~cm}^{2}\right)$ to $15 \times 30 \mathrm{~cm}\left(450 \mathrm{~cm}^{2}\right)$ and were located either posteriorly $(n=4)$ or anteriorly $(n=1)$. Associated injuries included open fractures $(n=3)$ and motor nerve transection $(n=2)$. Wound coverage was achieved in a mean duration of 18.8 days (range, 11 to 42 day). There were no flap failures and no major complications. The mean postoperative active elbow motion was $102^{\circ}$ (range, $45^{\circ}$ to $140^{\circ}$ ).

Conclusions In our small series we have highlighted the safety and utility of using the free ALT flap in complex elbow injuries. The ALT flap has many advantages which include abundant skin and subcutaneous tissue; vascularised vastus lateralis muscle that was used in our series to obliterate dead space, provide a vascular bed for nerve grafts and combat infection; and, access to fascia lata grafts for reconstruction of the triceps tendon.

Keywords Free tissue flaps / Elbow joint / Reconstructive surgical procedures
Correspondence: Bien-Keem Tan Department of Plastic, Reconstructive and Aesthetic Surgery, Outram Road, Singapore General Hospital, Singapore 169608

Tel: $+65-6321-4686$

Fax : $+65-6225-9340$

E-mail: bienkeem@singnet.com.sg

\begin{abstract}
This article was present at Chang Gung Mayo Clinic Symposium in Reconstructive Surgery, October 27-30, 2011.
\end{abstract}

No potential conflict of interest relevant to this article was reported.

Received: 6 Dec $2011 \bullet$ Revised: 14 Jan 2012 • Accepted: 15 Jan 2012

pISSN: 2234-6163 • elSSN: 2234-6171 • http://dx.doi.org/10.5999/aps.2012.39.2.130 • Arch Plast Surg 2012;39:130-136

\section{INTRODUCTION}

The elbow joint is prone to develop post-injury stiffness and its prevention is of paramount importance for a successful outcome. The final outcome in patients with complex elbow injuries is largely dependent on the extent of the initial injury [1]. Soft tissue defects less than $40 \mathrm{~cm}^{2}$ are associated with the greatest return of motion [2]. Larger defects and more complex injuries with associated nerve, muscle, or joint injury are associated with higher degrees of stiffness. In order to preserve function, joint congruency, elbow stability and durable wound coverage with a flap are needed. Joint mobility must be maintained by early motion. The flap should allow some gliding between the skin and underlying joint and should not hamper secondary surgical 
procedures such as capsulectomy and osteotomy. The purpose of this article is to present our approach to complex elbow injuries and share our experience using the free anterolateral thigh (ALT) flap for soft tissue coverage.

\section{METHODS}

\section{Surgical technique}

Thorough debridement of the wound and initial stabilisation with external fixation, if needed, is performed. Static external fixators are used temporarily to stabilize the joint until the patient is ready for definitive fixation. Meanwhile, negative pressure wound therapy is used to seal the wound and prevent infection.

Definitive fixation aims to restore articular congruity, re-establish anatomic mechanical axes, and obtain enough fracture stability to allow early, unrestricted elbow range of motion. The patient is deemed ready when the wound is healthy and free of infection. This decision is made jointly with the orthopaedic surgeons.

The ALT flap is harvested as previously described [3]. A fasciocutaneous perforator flap or musculocutaneous flap is harvested based on the reconstructive needs. A musculocutaneous flap is preferred when we need to cover bulky hardware, obliterate dead space or when bone or nerve grafting is performed. The skin paddle is designed so that it is of sufficient size to cover the anastomosis and close the defect without tension. The proximal brachial artery is the preferred site of anastomosis and end-to-side using a slit arteriotomy is performed to preserve the distal run-off [4]. Venous anastomosis is done end-to-end to the venae comitantes of the brachial artery or the basilic vein. Alternatively, the radial or ulnar arteries can be turned up for the arterial anastomosis, and they are usually used in conjunction with the basilic or cephalic vein for venous drainage.

Flap harvest is done concurrently with fixation. During inset of the flap, care is taken to ensure complete muscle wrap of hardware, bone and nerve grafts. Any dead space is obliterated with vascularised muscle. Postoperatively the elbow is splinted in $30^{\circ}$ of flexion and elevated. Mobilisation exercises are started after 7 days.

\section{Patients}

Case 1

A 40-year-old male was a driver of a car that overturned in a road traffic accident. He sustained a Gustilo IIIB open fracture dislocation of the right olecranon with degloving injury and $10 \mathrm{~cm}$

\section{Fig. 1. Gustilo IIIB fracture of the olecranon, degloving injury and $10 \mathrm{~cm}$ ulnar nerve loss}

(A) Open comminuted fracture dislocation of the elbow with temporary external fixation. (B) Radiograph of the right elbow after internal fixation with $3.5 \mathrm{~mm}$ reconstruction plate. (C) Segmental ulnar nerve loss (yellow arrows indicate nerve ends). (D) Ulnar nerve was repaired with a 3-cable sural nerve graft buried within flexor/pronator muscle complex. $(E, F)$ Nine year follow-up. Elbow range of motion: $45^{\circ}$ (range, $45^{\circ}$ to $\left.90^{\circ}\right)$. Ulnar nerve motor recovery grade M4. Patient demonstrates good hand opening and abduction of digits (E) as well as strong power grip (F).
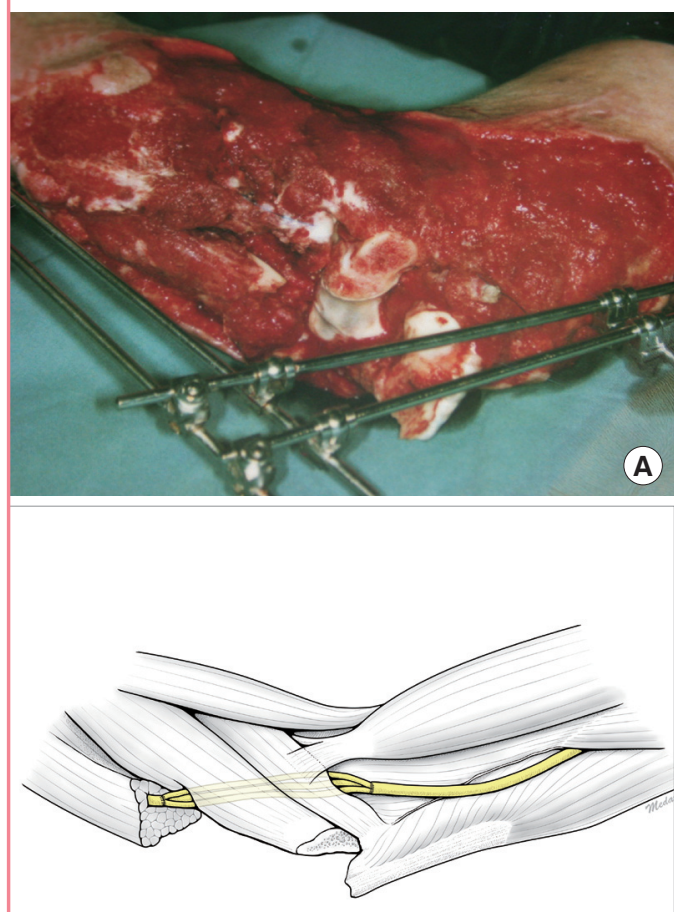

(D)
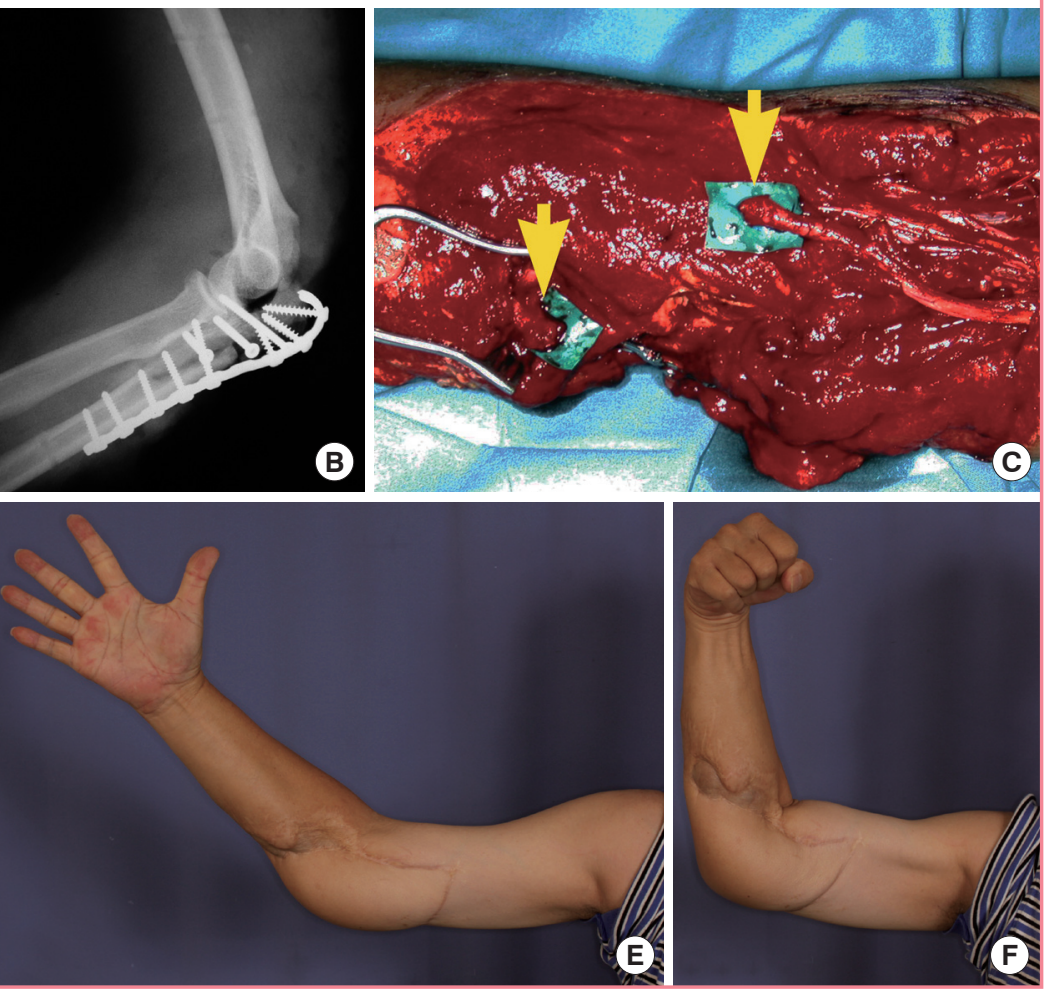
segmental loss of the right ulnar nerve (Fig. 1A, B). Initial management included multiple wound debridement and external fixation. 11 days after injury, internal fixation of the olecranon was performed. The ulnar nerve gap was bridged with a 3-cable sural nerve graft (Fig. 1C, D). A free ALT musculocutaneous flap was used to cover the elbow. The nerve grafts were buried in the forearm flexor/pronator muscle mass and covered with vastus lateralis muscle. The affected limb was immobilized in extension for 7 days. Despite using a flap with very well vascularised muscle, due to the severity of the injury and degree of comminution, he later developed septic arthritis and osteomyelitis necessitating removal of the implants. Heterotopic ossification developed subsequently. At latest review at 9 years 2-point discrimination was $7 \mathrm{~mm}$, he had regained full hand function (intrinsic muscle power 4/5) and active range of motion at the elbow was $45^{\circ}$ (range, $45^{\circ}$ to $90^{\circ}$ ) (Fig. 1E, F). He declined further surgery.

\section{Case 2}

A 34-year-old car driver was involved in a road traffic accident. He sustained a Gustilo IIIB open fracture dislocation of the right capitulum and radial head, segmental loss of the radial nerve, and anterior elbow skin loss measuring $15 \times 10 \mathrm{~cm}$. Surgical debridement was repeated until the wound was clean. Reduction of the radial head, sural nerve grafting for the radial nerve gap and free ALT flap coverage was performed 15 days after the initial trauma. No recovery of radial nerve function was observed and tendon transfers to restore wrist extension were performed. Eight months post elbow reconstruction his active elbow motion was $110^{\circ}$ (range, $0^{\circ}$ to $110^{\circ}$ ).

\section{Case 3}

A 40-year-old male was a front seat passenger in a car involved

Fig. 3. Triceps tendon reconstruction and ALT flap coverage Infection of previous fixation of olecranon fracture resulting in septic arthritis and wound breakdown. Picture shows secondary reconstruction of the triceps tendon with a rolled fascia lata graft (yellow arrow). The soft tissue defect was successfully covered with a free anterolateral thigh (ALT) musculocutaneous flap (not shown).

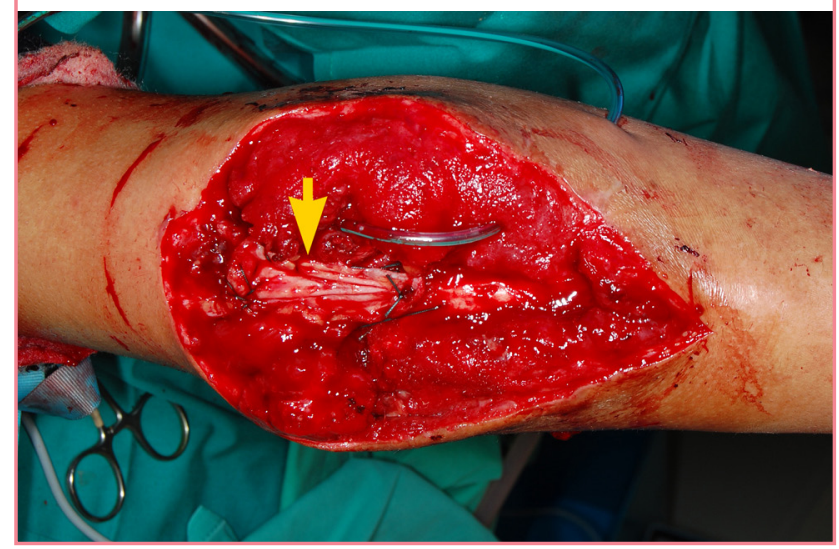

\section{Fig. 2. Crush injury of the left elbow with open humerus and ulna fractures}

(A) Open transverse humeral fracture, comminuted olecranon fracture with internal fixation with contoured low contact dynamic compression (LCDC) plates. (B) Internal fixation with contoured LCDC plates. (C) End-to-side arterial anastomosis (yellow arrow) to the brachial artery (BA) to preserve distal circulation. Venous anastomosis to the vena comitans (VC). (D, E) Nineteen month follow-up. Elbow range of motion: $115^{\circ}\left(15^{\circ}\right.$ to $\left.130^{\circ}\right)$.
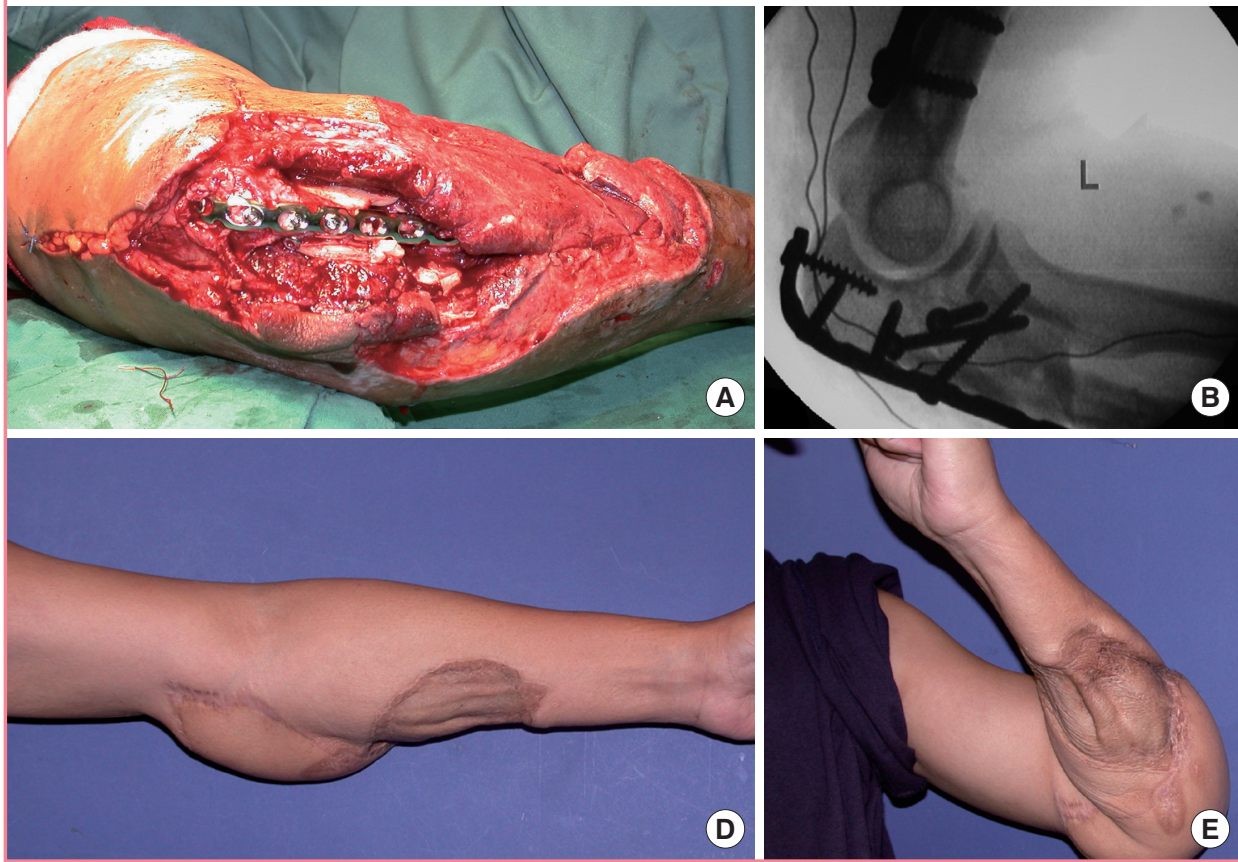

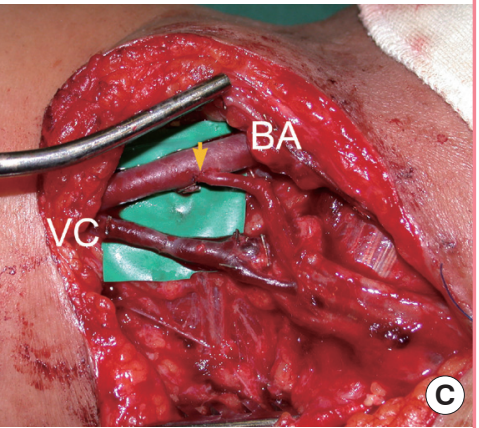

(1) 
in a road traffic accident. He sustained fractures of the left 1 st to 6th ribs, a left sided pneumothorax, pneumomediastinum, left scapula fracture, dislocation of the left little finger PIPJ as well as a crush injury of the left elbow with open fracture of the left humerus and proximal ulna. A chest tube was inserted and the little finger reduced. The elbow wound underwent debridement followed by external fixation and negative pressure dressing. Internal fixation of the humerus and ulna and soft tissue coverage with a free ALT flap were performed 13 days following injury. Nineteen months postoperatively active elbow motion was $115^{\circ}$ (range, $15^{\circ}$ to $130^{\circ}$ ) (Fig. 2).

\section{Case 4}

A 22-year-old prison inmate sustained a closed fracture of his right olecranon after a fall. Operative fixation of his fracture was complicated by wound infection, breakdown and bony non-union. Mycobacterium tuberculosis was isolated from the wound. After multiple wound debridements and negative pressure wound therapy, the triceps tendon was anchored to the olecranon and reinforced with a tensor fascia lata graft, immediate soft tissue coverage was achieved with a free ALT flap. A sinus developed at the flap edge that resolved after debridement and antimycobacterial treatment. At the most recent follow-up 2 years post reconstruction he can actively flex his elbow $100^{\circ}$ (range, $30^{\circ}$ to $130^{\circ}$ ) (Fig. 3 ).

\section{Case 5}

A 61-year-old man sustained a left olecranon avulsion fracture after he tripped and fell, landing on his left elbow. His repair was complicated by staphylococcus aureus wound infection requiring removal of hardware, debridement and negative pressure wound therapy. A free ALT perforator flap based on the oblique branch of the lateral circumflex femoral artery was used for soft tissue coverage once the infection was cleared. Two months after

\section{Fig. 4. Small anterolateral thigh perforator flap for soft tissue coverage}

(A) Infected repair of triceps tendon avulsion. (B) Anterolateral thigh perforator flap based on oblique branch of lateral circumflex femoral artery. (C) Postoperatively result at 1 month.
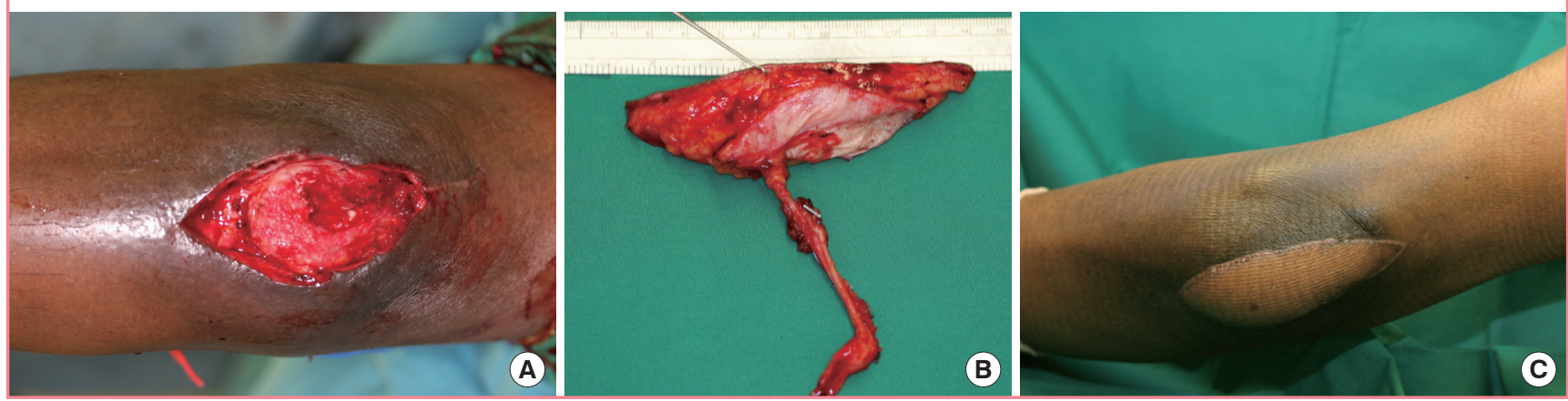

Table 1. Summary of patients, treatments and results

\begin{tabular}{|c|c|c|c|c|c|c|c|c|}
\hline Patient & $\begin{array}{l}\text { Age } \\
(\mathrm{yr})\end{array}$ & Sex & Cause of injury & Injuries & Treatment & Type of ALT flap & $\begin{array}{l}\text { Time to } \\
\text { coverage } \\
\text { (day) }\end{array}$ & Elbow motion $\left(^{\circ}\right)$ \\
\hline 1 & 40 & $\mathrm{M}$ & Trauma & $\begin{array}{l}\text { Gustilo IIIB olecranon fracture, } \\
\text { segmental loss of ulnar nerve, } \\
\text { skin defect: } 12 \times 20 \mathrm{~cm}\end{array}$ & $\begin{array}{l}\text { ORIF, } \\
\text { sural nerve } \\
\text { grafting }\end{array}$ & $\begin{array}{l}\text { Musculocutaneous } \\
\text { LCFA branch: } \\
\text { descending }\end{array}$ & 11 & $\begin{array}{c}45 \\
(45-90)\end{array}$ \\
\hline 2 & 34 & $\mathrm{M}$ & Trauma & $\begin{array}{l}\text { Gustilo IIIB fracture dislocation of radial } \\
\text { head, segmental loss of radial nerve, } \\
\text { skin defect: } 15 \times 10 \mathrm{~cm}\end{array}$ & $\begin{array}{l}\text { ORIF, } \\
\text { sural nerve } \\
\text { grafting }\end{array}$ & $\begin{array}{l}\text { Musculocutaneous } \\
\text { LCFA branch: } \\
\text { descending }\end{array}$ & 15 & $\begin{array}{c}110 \\
(0-110)\end{array}$ \\
\hline 3 & 40 & $\mathrm{M}$ & Trauma & $\begin{array}{l}\text { Rib fractures, pneumothorax, } \\
\text { open fracture of humerus and ulna, } \\
\text { scapula fracture, dislocation of PIPJ of } \\
\text { little finger, skin defect: } 15 \times 30 \mathrm{~cm}\end{array}$ & ORIF & $\begin{array}{l}\text { Musculocutaneous } \\
\text { LCFA branch: } \\
\text { descending }\end{array}$ & 13 & $\begin{array}{c}115 \\
(15-130)\end{array}$ \\
\hline 4 & 22 & $\mathrm{M}$ & $\begin{array}{l}\text { Postoperative } \\
\text { infection }\end{array}$ & $\begin{array}{l}\text { Closed fracture of olecranon, } \\
\text { skin defect: } 8 \times 15 \mathrm{~cm}\end{array}$ & $\begin{array}{l}\text { Triceps tendon } \\
\text { reconstruction } \\
\text { with fascia lata } \\
\text { graft }\end{array}$ & $\begin{array}{l}\text { Musculocutaneous } \\
\text { LCFA branch: } \\
\text { descending }\end{array}$ & 42 & $\begin{array}{c}100 \\
(30-130)\end{array}$ \\
\hline 5 & 61 & $\mathrm{M}$ & $\begin{array}{l}\text { Postoperative } \\
\text { infection }\end{array}$ & $\begin{array}{l}\text { Triceps avulsion, } \\
\text { skin defect: } 4 \times 9 \mathrm{~cm}\end{array}$ & $\begin{array}{l}\text { Triceps tendon } \\
\text { reattachment }\end{array}$ & $\begin{array}{l}\text { Fasciocutaneous } \\
\text { perforator } \\
\text { LCFA branch: oblique }\end{array}$ & 13 & $\begin{array}{c}140 \\
(0-140)\end{array}$ \\
\hline
\end{tabular}


coverage active elbow flexion is $140^{\circ}$ (range, $0^{\circ}$ to $140^{\circ}$ ) (Fig. 4).

\section{RESULTS}

A summary of patients, treatments and results can be found in Table 1. The mean age of the patients was 39.4 years (range, 22 to 61 years). All were male. The defects were secondary to trauma $(n=3)$, post-surgical infection $(n=2)$ was the other cause. Soft tissue defects ranged in size from $4 \times 9 \mathrm{~cm}\left(36 \mathrm{~cm}^{2}\right)$ to $15 \times 30 \mathrm{~cm}\left(450 \mathrm{~cm}^{2}\right)$ and were located either posteriorly $(n=4)$ or anteriorly $(n=1)$. Associated injuries included open fractures $(n=3)$ and motor nerve transection $(n=2)$. All cases had vital structures to be covered -orthopaedic hardware $(n=2)$, exposed bone $(n=4)$, or exposed triceps tendon $(n=1)$. Fasciocutaneous $(n=1)$ and musculocutaneous flaps $(n=4)$ were used. Arterial revascularisation was performed end-toside to the brachial artery $(n=4)$ and end-to-end to a recurrent branch of the brachial artery $(n=1)$. Wound coverage was achieved in a mean duration of 18.8 days (range, 11 to 42 days). Minor complications included wound infection $(n=2)$ and heterotopic ossification $(n=1)$. There were no flap failures and no major complications. Postoperative wound infection One patient suffered a prolonged local infection with mycobacterium tuberculosis. The mean postoperative active elbow motion was $102^{\circ}$ (range, $45^{\circ}$ to $140^{\circ}$ ).

\section{DISCUSSION}

In this series of patients with medium to large elbow defects, the goals of stable internal fixation and durable skin coverage were achieved by collaboration between the orthopaedic and plastic surgeons. Successful coverage allowed early aggressive joint mobilisation.

Orthopaedic fixation was used to treat bony and soft tissue injury, and soft tissue coverage was performed when the wound was deemed clean and free of infection. Elbow fractures were reduced and internally fixated with preservation of articular congruity using devices such as the $3.5 \mathrm{~mm}$ reconstruction plate, 3.5 $\mathrm{mm}$ low contact dynamic compression plates as well as anatomical locking plates e.g., proximal ulnar locking compression plates. Successful operative treatment depends on restoring joint congruency (especially the ulnohumeral joint) and elbow stability, so that early joint motion is possible [5]. Dead space at the fracture site can be a problem if the implants do not conform exactly to the bone surface or if there is a bone gap. A well vascularised muscle can fill the dead space and reduce the risk of infection.

Many local and pedicled flaps have been described for elbow reconstruction. Local flaps are indicated for small defects with healthy adjacent skin. Common designs include rotation flaps, transposition flaps, and perforator based island flaps. However, they cannot be used if there is extensive degloving injury. Pedicled flaps such as the radial foream, ulnar forearm, antecubital fasciocutaneous, and posterior interosseous flaps have been used, however, the disadvantages are extensive scarring and the need for skin grafting over the forearm. Muscles such as flexor carpi ulnaris, brachioradialis, and anconeus can be elevated to provide coverage of small areas but at the sacrifice of some limb function [6]. The pedicled latissimus dorsi flap is a traditional workhorse flap for coverage of large elbow defects, especially proximal to the olecranon. When used for defects beyond the olecranon it has a propensity for distal tip necrosis, wound breakdown or failure [2]. Free flaps are indicated for large defects distal to the olecranon [7].

Although free tissue transfer has become increasingly popular, it has not been emphasised sufficiently for elbow coverage. The English literature contains relatively few reports on its use. Hallock used five local fascial flaps and three free flaps for elbow coverage in his series of upper extremity trauma [6]. He advocated using local flaps for mild injuries but maintained that free flaps were necessary in larger or composite defects. Choudry et al. [2] reported using free tissue transfers in only $19 \%$ of cases in their series of 96 patients requiring soft tissue coverage of the elbow. Of the 19 free flaps, only five (26\%) were ALT flaps, with the latissimus dorsi being the flap of choice (42\%). This may stem from the perception that the vascular supply of the ALT flap is unreliable, although recent studies have defined its vascular anatomy and proven the flap's reliability $[8,9]$. Other than the ALT flap, perforator flaps including the thoracodorsal artery perforator [10-12] and superficial circumflex iliac artery perforator [13] flaps offer reliable skin cover.

The ALT flap is ideal for elbow coverage. It can provide large amounts of skin (up to $35 \mathrm{~cm}$ long and $25 \mathrm{~cm}$ wide can be harvested on a single dominant perforator [14]) as well as vastus lateralis muscle, which can be used to obliterate dead space and combat infection. Furthermore, vascularised muscle helps to vascularise the sural nerve grafts $[15,16]$ and optimise outcome as seen in case 1 . The motor nerve to the vastus lateralis could potentially be used as a vascularised nerve graft [17]. Even if the motor nerve is harvested, or the vastus lateralis muscle is included in the flap, donor site morbidity is acceptable and studies have shown that all patients eventually return to their preoperative level of function $[18,19]$.

Fascia lata grafts are easily harvested at the time of flap elevation and can be used to reconstruct the triceps tendon (case 4) or elbow ligaments. Primary closure of the donor site is possible if the skin paddle is $\leq 7$ to $9 \mathrm{~cm}$ wide [14], but the donor site 
is skin grafted if a larger skin paddle is needed. The skin paddle should cover the vascular anastomoses and be sufficiently large to accommodate the hardware and allow the elbow to move freely. Since the donor site is located a distance from the elbow, harvest of the flap can proceed concurrently with the other elbow procedures. A thin flap can be obtained by elevating in a suprafascial plane [20] or by trimming of the subcutaneous fat to the subdermal level $[21,22]$. The skin paddle of the ALT flap allows fast skin-to-skin healing at the interface between the flap and the wound edge and its subcutaneous tissue allows gliding between the joint and skin.

Loss of movement after injury to the elbow is common. Sojbjerg [1] defined a stiff elbow as one with flexion of less than $120^{\circ}$ and a loss of extension of greater than $30^{\circ}$, Morrey et al. [23] found that most tasks of daily living can be performed with $100^{\circ}$ of elbow motion (from $30^{\circ}$ to $130^{\circ}$ ). All of our patients displayed $\geq 100^{\circ}$ of elbow flexion except for patient 1 , who had elbow flexion of $45^{\circ}$ (range, $45^{\circ}$ to $90^{\circ}$ ). Although his elbow was stiff, he had excellent ulnar nerve recovery and declined further surgery.

The causes of posttraumatic elbow stiffness are varied and can be classified as intrinsic or extrinsic. Heterotopic ossification, as occurred in patient 1 , is the most common cause of extrinsic elbow contracture and it is characterised by progressive ossification of periarticular soft tissues [24]. Operative release of the stiff elbow depends on the aetiology but usually involves release of the posterior band of the medial collateral ligament, debridement of any bony blocks to motion and/or anterior and posterior capsulectomy [25]. Total elbow arthroplasty may be considered in selected cases [25]. The ALT skin paddle affords skin-toskin healing and facilitates secondary surgery of the elbow.

In conclusion, the advantages of the ALT flap for elbow coverage are 1) abundant skin and subcutaneous tissue; 2) vascularised vastus lateralis muscle that can be used to obliterate dead space, provide a vascular bed for nerve grafts and combat infection; and, 3) access to fascia lata grafts for triceps tendon repair.

\section{REFERENCES}

1. Sojbjerg JO. The stiff elbow. Acta Orthop Scand 1996;67: 626-31.

2. Choudry UH, Moran SL, Li S, et al. Soft-tissue coverage of the elbow: an outcome analysis and reconstructive algorithm. Plast Reconstr Surg 2007;119:1852-7.

3. Wong $\mathrm{CH}$, Wei FC. Anterolateral thigh flap. Head Neck 2010;32:529-40.

4. Tan BK, Wong CH, Chew W, et al. Use of the slit arteriotomy for end-to-side arterial anastomosis in free-tissue trans- fers to the extremities. J Plast Reconstr Aesthet Surg 2009; 62:1519-23.

5. Lee DH. Treatment options for complex elbow fracture dislocations. Injury 2001;32 Suppl 4:SD41-69.

6. Hallock GG. The utility of both muscle and fascia flaps in severe upper extremity trauma. J Trauma 2002;53:61-5.

7. Jensen M, Moran SL. Soft tissue coverage of the elbow: a reconstructive algorithm. Orthop Clin North Am 2008;39: 251-64.

8. Wong $\mathrm{CH}$, Wei FC, Fu B, et al. Alternative vascular pedicle of the anterolateral thigh flap: the oblique branch of the lateral circumflex femoral artery. Plast Reconstr Surg 2009;123: 571-7.

9. Yu P. Characteristics of the anterolateral thigh flap in a Western population and its application in head and neck reconstruction. Head Neck 2004;26:759-69.

10. Chen SL, Chen TM, Wang HJ. Free thoracodorsal artery perforator flap in extremity reconstruction: 12 cases. $\mathrm{Br} \mathrm{J}$ Plast Surg 2004;57:525-30.

11. Kim JT, Koo BS, Kim SK. The thin latissimus dorsi perforator-based free flap for resurfacing. Plast Reconstr Surg 2001; 107:374-82.

12. Ayhan S, Tuncer S, Demir Y, et al. Thoracodorsal artery perforator flap: a versatile alternative for various soft tissue defects. J Reconstr Microsurg 2008;24:285-93.

13. Koshima I, Nanba Y, Tsutsui T, et al. Superficial circumflex iliac artery perforator flap for reconstruction of limb defects. Plast Reconstr Surg 2004;113:233-40.

14. Mardini S, Lin LC, Moran SL, et al. Anterolateral thigh flap. In: Wei FC, Mardini S, editors. Flaps and reconstructive surgery. Philadelphia: Elsevier; 2009. p. 538-58.

15. Cho HK, Lee DJ, Cha JH, et al. Nerve regeneration after autogenous nerve graft using perfabricated adiponeural and myoneural flap: an experimental study. J Korean Soc Plast Reconstr Surg 2000;27:65-71.

16. Prpa B, Huddleston PM, An KN, et al. Revascularization of nerve grafts: a qualitative and quantitative study of the softtissue bed contributions to blood flow in canine nerve grafts. J Hand Surg Am 2002;27:1041-7.

17. Koshima I, Nanba Y, Tsutsui T, et al. Vascularized femoral nerve graft with anterolateral thigh true perforator flap for massive defects after cancer ablation in the upper arm. J Reconstr Microsurg 2003; 19:299-302.

18. Hanasono MM, Skoracki RJ, Yu P. A prospective study of donor-site morbidity after anterolateral thigh fasciocutaneous and myocutaneous free flap harvest in 220 patients. Plast Reconstr Surg 2010;125:209-14.

19. Townley WA, Royston EC, Karmiris N, et al. Critical assess- 
ment of the anterolateral thigh flap donor site. J Plast Reconstr Aesthet Surg 2011;64:1621-6.

20. Wei FC, Jain V, Suominen S, et al. Confusion among perforator flaps: what is a true perforator flap? Plast Reconstr Surg 2001;107:874-6.

21. Kimura N, Satoh K. Consideration of a thin flap as an entity and clinical applications of the thin anterolateral thigh flap. Plast Reconstr Surg 1996;97:985-92.

22. Kimata Y, Uchiyama K, Ebihara S, et al. Versatility of the free anterolateral thigh flap for reconstruction of head and neck defects. Arch Otolaryngol Head Neck Surg 1997;123:1325-31.

23. Morrey BF, Askew LJ, Chao EY. A biomechanical study of normal functional elbow motion. J Bone Joint Surg Am 1981; 63:872-7.

24. Keschner MT, Paksima N. The stiff elbow. Bull NYU Hosp Jt Dis 2007;65:24-8.

25. Evans PJ, Nandi S, Maschke S, et al. Prevention and treatment of elbow stiffness. J Hand Surg Am 2009;34:769-78. 


\section{Discussion}

\section{Discussion: Use of the Fix and Flap Approach to Complex Open Elbow Injury: The Role of the Free Anterolateral Thigh} Flap

Yixin Zhang

Department of Plastic and Reconstructive Surgery, Shanghai Ninth People's Hospital, Shanghai Jiaotong University School of Medicine, Shanghai, China

\section{Current concepts in the management of elbow trauma}

Due to the complexity of the structures that are necessary for adequate joint function, elbow trauma remains a challenging injury even for the experienced trauma surgeon. Severe soft tissue loss requires appropriate covering of the underlying structures [1]. The workhorses for elbow cover in the past were the pedicled latissimus dorsi flap and the radial forearm flap; the application of the use of regional flaps depended on the extent of the injury. With the use of pedicled latissimus dorsi flaps, the complication rates are high if the injuries extend distally to the olecranon [2].

\section{The alt flap: advantages and disadvantages}

The free anterolateral thigh (ALT) flap is becoming a preferred option for soft-tissue reconstruction and its clinical applications have been broadened [3]. It is a septocutaneus or musculocutaneus flap based on the perforators from the descending branch of the circumflex femoral artery, which could provide a large amount of soft tissue for wound coverage. Adjacent tissue, such as a portion of the vastus lateralis and part of the fascial lata can be harvested as a chimeric-style flap based on its different perforators simultaneously if necessary. Another major factor in elbow reconstructions is the fact that the ALT flap enclosed with the lateral femoral cutaneous nerve provides protective sensibility, which is especially important in the upper limb. A major shortcoming of this flap is its anatomic variation, but with a preoperative Doppler study and a precise intraoperative perforator dissection, the risks of flap failure can be minimized [4-6]

There is little published data on the application of the ALT flap to elbow covering. The detailed study of Choudry et al. [1] showed excellent results by using the ALT free flap and Wang et al. [6] advocated the ALT flap for reconstruction in injuries to the upper extremity.

\section{Summary}

Fast improvements in microsurgery have opened new strategies in the field of reconstructive trauma surgery that can be applied to severe elbow trauma management. The disadvantages of pedicle flaps can be overcome in the hand of an experienced trauma surgeon by using free flaps based on the perforators. This provides the patient with the best possible wound cover within the optimal time frame and the treatment of underlying additional structural damage.

Although the authors presented only a small number of cases, the results of this study are promising and encourage the use of the ALT flap for the treatment of severe elbow trauma.

\section{REFERENCES}

1. Choudry UH, Moran SL, Li S, et al. Soft-tissue coverage of the elbow: an outcome analysis and reconstructive algorithm. Plast Reconstr Surg 2007;119:1852-7.

2. Stevanovic M, Sharpe F, Itamura JM. Treatment of soft tissue problems about the elbow. Clin Orthop Relat Res 2000; (370):127-37.

3. Wei FC, Jain V, Celik N, et al. Have we found an ideal softtissue flap? An experience with 672 anterolateral thigh flaps. Plast Reconstr Surg 2002;109:2219-26.

4. Celik N, Wei FC, Lin $\mathrm{CH}$, et al. Technique and strategy in anterolateral thigh perforator flap surgery, based on an analysis of 15 complete and partial failures in 439 cases. Plast Reconstr Surg 2002;109:2211-6.

5. Kawai K, Imanishi N, Nakajima H, et al. Vascular anatomy of the anterolateral thigh flap. Plast Reconstr Surg 2004;114: 1108-17.

6. Wang HT, Fletcher JW, Erdmann D, et al. Use of the anterolateral thigh free flap for upper-extremity reconstruction. J Hand Surg Am 2005;30:859-64.

\section{Correspondence: Yixin Zhang}

Department of Plastic and Reconstructive Surgery, Shanghai Ninth People's Hospital,

Shanghai Jiaotong University School of Medicine, 639 Zhizaoju Road, Shanghai 200011, P. R. China

Tel: +86-13061775858, Fax: +86-21-630518588, E-mail: Zhangyixin6688@hotmail.com

No potential conflict of interest relevant to this article was reported.

Received: 21 Feb 2012 • Revised: 22 Feb 2012 • Accepted: 23 Feb 2012

pISSN: 2234-6163 - elSSN: 2234-6171

http://dx.doi.org/10.5999/aps.2012.39.2.137 • Arch Plast Surg 2012;39:137

Copyright () 2012 The Korean Society of Plastic and Reconstructive Surgeons

This is an Open Access article distributed under the terms of the Creative Commons Attribution Non-Commercial License (http://creativecommons.org/

licenses/by-nc/3.0/) which permits unrestricted non-commercial use, distribution, and reproduction in any medium, provided the original work is properly cited. I www.e-aps.org 